Article

\title{
Depsidomycins B and C: New Cyclic Peptides from a Ginseng Farm Soil-Derived Actinomycete
}

\author{
Yun Kwon ${ }^{1}$, Woong Sub Byun ${ }^{1}$, Byung-Yong Kim ${ }^{2}$, Myoung Chong Song ${ }^{3}{ }^{(\mathbb{D}}$, Munhyung Bae ${ }^{1}$, \\ Yeo Joon Yoon ${ }^{3}$, Jongheon Shin ${ }^{1}$, Sang Kook Lee ${ }^{1}$ and Dong-Chan Oh ${ }^{1, *}$ \\ 1 Natural Products Research Institute, College of Pharmacy, Seoul National University, Seoul 08826, \\ Republic of Korea; kisi2016@snu.ac.kr (Y.K.); sky_magic@naver.com (W.S.B.); baemoon89@snu.ac.kr (M.B.); \\ shinj@snu.ac.kr (J.S.); sklee61@snu.ac.kr (S.K.L.) \\ 2 ChunLab, Inc., JW TOWER, Seocho-gu, Seoul 06725, Republic of Korea; greg6044@gmail.com \\ 3 Department of Chemistry and Nanoscience, Ewha Womans University, Seoul 03760, Republic of Korea; \\ smch517@ewha.ac.kr (M.C.S.); joonyoon@ewha.ac.kr (Y.J.Y.) \\ * Correspondence: dongchanoh@snu.ac.kr; Tel.: +82-288-024-91
}

Received: 28 April 2018; Accepted: 24 May 2018; Published: 25 May 2018

\begin{abstract}
LC/MS-based chemical profiling of a ginseng farm soil-derived actinomycete strain, Streptomyces sp. BYK1371, enabled the discovery of two new cyclic heptapeptides, depsidomycins B and C (1 and 2), each containing two piperazic acid units and a formyl group at their $N$-terminus. The structures of $\mathbf{1}$ and $\mathbf{2}$ were elucidated by a combination of spectroscopic and chemical analyses. These new compounds were determined to possess D-leucine, D-threonine, D-valine, and S-piperazic acid based on the advanced Marfey's method and a GITC (2,3,4,6-tetra-O-acetyl- $\beta$-D-glucopyranosyl isothiocyanate) derivatization of their hydrolysates, followed by LC/MS analysis. Depsidomycins $B$ and $C$ displayed significant antimetastatic activities against metastatic breast cancer cells (MDA-MB-231).
\end{abstract}

Keywords: farm soil; actinomycete; Streptomyces sp.; cyclic peptide; antimetastatic

\section{Introduction}

Secondary metabolites from soil bacteria have been prolific sources of bioactive natural products for the last century, and they have provided a number of important clinical drugs [1]. However, exhaustive studies of soil bacteria with conventional strategies involving bioassay-guided fractionation have shown decreasing success rates in the discovery of new bacterial secondary metabolites. The recent development of chemical analysis-based search methods has enabled the efficient discovery of new bioactive compounds from bacteria [2]. Our time-course chemical analysis of bacterial metabolites using LC/MS chemical profiling yielded new chemotypes, demonstrating the value of chemical analysis-based research in natural products chemistry. A recent example of the success of such a method is the discovery of a novel pyrazolone-bearing metabolite from a Streptomyces strain collected in an intertidal mudflat [3]. A Deinococcus strain isolated from the gut of the carpenter ant, Camponotus japonicus, was found to produce new aminoglycolipids [4]. New naphthoquinone-oxindoles with a novel carbon framework were discovered from a gut bacterial strain of the dung beetle, Copris tripartitus [5]. For the efficient discovery of new bioactive small molecules from bacteria, a new paradigm of search strategies could be used to investigate poorly studied bacterial habitats. Farm soil appears readily accessible but has been essentially abandoned in natural product discovery, possibly because the environment can be regarded as anthropogenic rather than natural. However, the rhizosphere, a narrow region of farm soil, is a unique environment harboring microbial communities that interact with plant root exudates, which could allow these 
strains to produce unique secondary metabolites [6]. One of our pioneering studies on farm soil bacterial metabolites based on detailed LC/MS chemical profiling resulted in the discovery of a rare norditerpenoid with antibacterial activity from Actinomadura sp. inhabiting an experimental farm in the United Kingdom [7]. Our ongoing search for bioactive compounds from farm soil bacteria led us to investigate ginseng farm soil-derived actinomycetes. Ginseng, from the genus Panax, is considered one of the most valuable medicinal plants in many Asian countries including Korea [8]. Even though the chemistry of ginseng has been exhaustively studied because of its bioactive compounds [9], the chemistry of the bacterial communities of ginseng farm soil have not been examined. We collected soil from a farm cultivating Panax ginseng in Cheorwon, Gangwon-do, Republic of Korea. More than 100 bacterial strains were isolated from the ginseng farm soil. Chemical analyses of the bacteria were performed with a focus on the actinobacterial strains, which are the most prolific bacterial group for the production of small molecules [1]. Time-course chemical analyses of the actinobacterial strains conducted by LC/MS detected multiple unique metabolites with molecular ions $\left([\mathrm{M}+\mathrm{H}]^{+}\right)$at $m / z$ 792 and 778 from Streptomyces sp. BYK1371. Further large-scale culture and subsequent chemical analysis enabled the elucidation of the structures of these new compounds, and the compounds were named depsidomycins B and C (1 and 2, Figure 1). Here, we report their structure determination and biological activity.

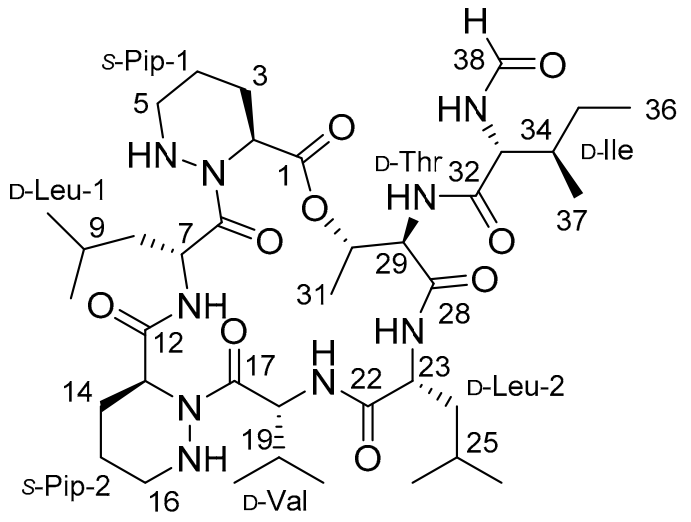

1

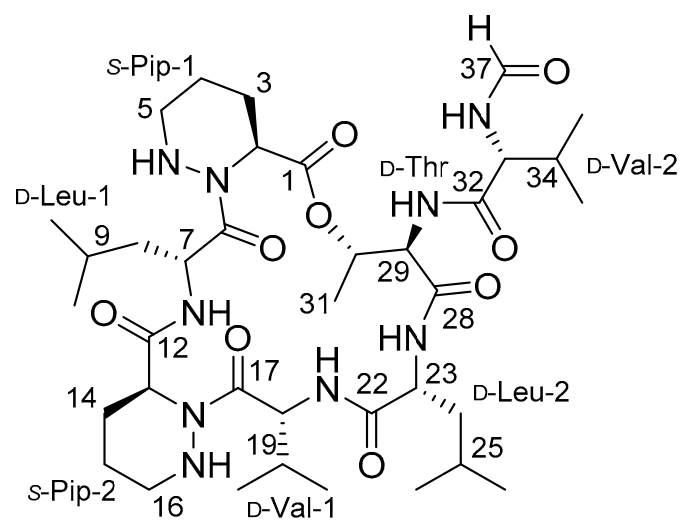

2

Figure 1. The chemical structures of depsidomycins B and C (1 and $\mathbf{2})$.

\section{Results and Discussion}

\subsection{Structure Elucidation}

Depsidomycin B (1) was isolated as a white, amorphous powder. The molecular formula of 1 was found to be $\mathrm{C}_{38} \mathrm{H}_{65} \mathrm{~N}_{9} \mathrm{O}_{9}$ on the basis of its HR-ESI-MS data. The ${ }^{13} \mathrm{C}$ NMR data confirmed the presence of 38 carbons, namely, eight carbonyl carbons $\left(\delta_{C} 161.8-175.9\right)$, one oxygen-bearing aliphatic carbon $\left(\delta_{C} 71.4\right)$, nine nitrogen-bearing carbons $\left(\delta_{C} 47.8-56.2\right)$, and 20 aliphatic carbons $\left(\delta_{C}\right.$ 41.4-11.9) (Table 1). Comprehensive analysis of the ${ }^{1} \mathrm{H},{ }^{13} \mathrm{C}$, and HSQC NMR spectroscopic data of 1 revealed the presence of seven $\mathrm{D}_{2} \mathrm{O}$ exchangeable protons $\left(\delta_{\mathrm{H}} 7.62,7.59,7.52,7.49,7.07,4.86\right.$, and 3.95), one formyl functional group $\left(\delta_{\mathrm{H}} 8.27 ; \delta_{\mathrm{C}} 161.8\right)$, nine aliphatic methylenes, twelve aliphatic methines, and nine methyl groups. The five downfield, heteroatom-bound protons $\left(\delta_{\mathrm{H}} 7.62-7.07\right)$ and eight carbonyl carbons in the amide/ester carbon chemical shift range indicated that depsidomycin $\mathrm{B}$ could be a modified peptide decorated with a formyl functional group. Eight of the eleven double bond equivalents inherent in the molecular formula of $\mathbf{1}$ could be attributed to carbonyl groups, which indicated the existence of three rings in the structure of depsidomycin B (1). 
Table 1. ${ }^{1} \mathrm{H}$ and ${ }^{13} \mathrm{C}$ NMR data of depsidomycins B and C (1 and 2) in acetone- $d_{6}{ }^{a}$.

\begin{tabular}{|c|c|c|c|c|}
\hline \multirow{2}{*}{ Position } & \multicolumn{2}{|c|}{ Depsidomycin B (1) } & \multicolumn{2}{|c|}{ Depsidomycin C (2) } \\
\hline & $\delta_{C}$, Type & $\delta_{\mathrm{H}}$, mult $(J \text { in } \mathrm{Hz})^{a}$ & $\delta_{C}$, Type & $\delta_{\mathrm{H}}$, mult $(J \text { in } \mathrm{Hz})^{a}$ \\
\hline 1 & $169.3, \mathrm{C}$ & & $170.0, \mathrm{C}$ & \\
\hline 2 & $51.4, \mathrm{CH}$ & 5.18, br s & $51.5, \mathrm{CH}$ & 5.17, br s \\
\hline $3 a$ & $23.4, \mathrm{CH}_{2}$ & $1.85, \mathrm{~m}$ & 23.3, $\mathrm{CH}_{2}$ & $1.87, \mathrm{~m}$ \\
\hline $3 b$ & & $2.19, \mathrm{~m}$ & & $2.19, \mathrm{~m}$ \\
\hline $4 a$ & 21.3, $\mathrm{CH}_{2}$ & $1.55, \mathrm{~m}$ & 21.9, $\mathrm{CH}_{2}$ & $1.55, \mathrm{~m}$ \\
\hline $4 \mathrm{~b}$ & & $1.86, \mathrm{~m}$ & & \\
\hline $5 a$ & $47.9, \mathrm{CH}_{2}$ & $3.12, \mathrm{~m}$ & $48.4, \mathrm{CH}_{2}$ & $3.15, \mathrm{~m}$ \\
\hline $5 b$ & & $2.85, \mathrm{~m}$ & & $2.85, \mathrm{~m}$ \\
\hline $5-\mathrm{NH}$ & & $4.86, \mathrm{~m}$ & & $4.85, \mathrm{~m}$ \\
\hline 6 & $175.4, \mathrm{C}$ & & $175.9, \mathrm{C}$ & \\
\hline 7 & $49.7, \mathrm{CH}$ & $5.40, \mathrm{dd}(10.5,10.5)$ & $49.4, \mathrm{CH}$ & $5.39, \mathrm{dd}(10.5,10.5)$ \\
\hline 7-NH & & 7.62, br d $(10.5)$ & & 7.60, br d $(10.5)$ \\
\hline $8 a$ & $41.4, \mathrm{CH}_{2}$ & $1.68, \mathrm{~m}$ & $41.9, \mathrm{CH}_{2}$ & $1.68, \mathrm{~m}$ \\
\hline $8 \mathrm{~b}$ & & $1.95, \mathrm{~m}$ & & $1.97, \mathrm{~m}$ \\
\hline 9 & $26.6, \mathrm{CH}$ & $1.78, \mathrm{~m}$ & $26.7, \mathrm{CH}$ & $1.78, \mathrm{~m}$ \\
\hline 10 & 21.0, $\mathrm{CH}_{3}$ & $1.02, \mathrm{~d}(6.5)$ & $21.9, \mathrm{CH}_{3}$ & $1.03, \mathrm{~d}(6.5)$ \\
\hline 11 & 23.7, $\mathrm{CH}_{3}$ & $0.93, \mathrm{~d}(6.5)$ & $19.7, \mathrm{CH}_{3}$ & $0.96, \mathrm{~d}(6.5)$ \\
\hline 12 & 167.7, C & & $168.5, \mathrm{C}$ & \\
\hline 13 & $52.8, \mathrm{CH}$ & $5.12, \mathrm{~d}(4.5)$ & $53.1, \mathrm{CH}$ & $5.11, \mathrm{~d}(4.5)$ \\
\hline $14 a$ & $24.9, \mathrm{CH}_{2}$ & $1.58, \mathrm{~m}$ & $25.5, \mathrm{CH}_{2}$ & $1.58, \mathrm{~m}$ \\
\hline $14 \mathrm{~b}$ & & 2.57, br d (13.5) & & 2.57, br d (13.3) \\
\hline $15 a$ & 23.0, $\mathrm{CH}_{2}$ & $1.39, \mathrm{~m}$ & 23.7, $\mathrm{CH}_{2}$ & $1.39, \mathrm{~m}$ \\
\hline $15 b$ & & 1.55, br d $(10.5)$ & & 1.55, br d $(10.5)$ \\
\hline $16 a$ & $47.8, \mathrm{CH}_{2}$ & $2.75, \mathrm{~m}$ & $48.5, \mathrm{CH}$ & $2.77, \mathrm{~m}$ \\
\hline $16 \mathrm{~b}$ & & $3.12, \mathrm{~m}$ & & $3.12, \mathrm{~m}$ \\
\hline $16-\mathrm{NH}$ & & $3.95, \mathrm{~d}(12.5)$ & & $3.94, d(12.5)$ \\
\hline 17 & $175.9, \mathrm{C}$ & & $175.9, \mathrm{C}$ & \\
\hline 18 & $56.2, \mathrm{CH}$ & $5.20, \mathrm{dd}(10.0,6.0)$ & $56.2, \mathrm{CH}$ & $5.20, \mathrm{dd}(10.5,6.0)$ \\
\hline $18-\mathrm{NH}$ & & $7.59, \mathrm{~d}(6.0)$ & & $7.58, \mathrm{~d}(6.0)$ \\
\hline 19 & $29,5, \mathrm{CH}$ & $1.99, \mathrm{~m}$ & $29.8, \mathrm{CH}$ & $1.99, \mathrm{~m}$ \\
\hline 20 & 21.0, $\mathrm{CH}_{3}$ & $1.02, \mathrm{~d}(6.5)$ & $20.8, \mathrm{CH}_{3}$ & $1.04, \mathrm{~d}(6.5)$ \\
\hline 21 & $19.7, \mathrm{CH}_{3}$ & $0.97, \mathrm{~d}(6.5)$ & $19.8, \mathrm{CH}_{3}$ & $0.97, \mathrm{~d}(6.5)$ \\
\hline 22 & $174.7, \mathrm{C}$ & & $175.7, \mathrm{C}$ & \\
\hline 23 & $51.0, \mathrm{CH}$ & $4.88, \mathrm{~m}$ & $51.7, \mathrm{CH}$ & $4.87, \mathrm{~m}$ \\
\hline 23-NH & & 7.07 , br s & & $7.05, \mathrm{~d}(9.5)$ \\
\hline $24 a$ & $408 \mathrm{CH}_{2}$ & $1.68, \mathrm{~m}$ & $416 \mathrm{CH}$ & $1.69, \mathrm{~m}$ \\
\hline $24 b$ & $40.8, \mathrm{CH}_{2}$ & $2.17, \mathrm{~m}$ & $41.6 \mathrm{CH}_{2}$ & $2.17, \mathrm{~m}$ \\
\hline 25 & $25.8, \mathrm{CH}$ & $1.71, \mathrm{~m}$ & $26.3, \mathrm{CH}$ & $1.70, \mathrm{~m}$ \\
\hline 26 & 20.6, $\mathrm{CH}_{3}$ & $0.89, \mathrm{~m}$ & $20.7, \mathrm{CH}_{3}$ & $0.89, \mathrm{~m}$ \\
\hline 27 & 24.0, $\mathrm{CH}_{3}$ & $0.91, \mathrm{~m}$ & & $0.90, \mathrm{~m}$ \\
\hline 28 & $167.4, \mathrm{C}$ & & $168.1, \mathrm{C}$ & \\
\hline 29 & $55.8, \mathrm{CH}$ & 4.48, br s & $55.8, \mathrm{CH}$ & $4.47, \mathrm{~m}$ \\
\hline 29-NH & & $7.52, \mathrm{br} \mathrm{s}$ & & $7.50, \mathrm{~d}(6.0)$ \\
\hline 30 & $71.4, \mathrm{CH}$ & $4.91, \mathrm{~m}$ & $72.0, \mathrm{CH}$ & $4.90, \mathrm{~m}$ \\
\hline 31 & $13.6, \mathrm{CH}_{3}$ & $1.17, \mathrm{~d}(6.5)$ & 13.6, $\mathrm{CH}_{3}$ & $1.17, \mathrm{~d}(6.5)$ \\
\hline 32 & $171.7, \mathrm{C}$ & & $171.6, \mathrm{C}$ & \\
\hline 33 & $55.4, \mathrm{CH}$ & $4.66, \mathrm{~m}$ & $57.3, \mathrm{CH}$ & $4.49, \mathrm{~m}$ \\
\hline 33-NH & & 7.49, br s & & 7.49, br d (6.5) \\
\hline 34 & $38.1, \mathrm{CH}$ & $1.98, \mathrm{~m}$ & $32.2, \mathrm{CH}$ & $2.18, \mathrm{~m}$ \\
\hline $35 a$ & $26.9, \mathrm{CH}_{2}$ & $1.21, \mathrm{~m}$ & $23.9, \mathrm{CH}_{3}$ & $0.93, d(6.5)$ \\
\hline $35 \mathrm{~b}$ & & $1.43, \mathrm{~m}$ & & \\
\hline 36 & $11.8, \mathrm{CH}_{3}$ & $0.90, \mathrm{~m}$ & 24.0. $\mathrm{CH}_{3}$ & $0.92, \mathrm{~d}(6.5)$ \\
\hline 37 & $14.6, \mathrm{CH}_{3}$ & $0.87, \mathrm{~d}(7.0)$ & 161.7, $\mathrm{CH}$ & $8.25, \mathrm{~s}$ \\
\hline 38 & $161.8, \mathrm{CH}$ & $8.27, \mathrm{~s}$ & & \\
\hline
\end{tabular}

After establishing 1-bond ${ }^{1} \mathrm{H}_{-}{ }^{13} \mathrm{C}$ correlations, structural fragments were assembled based on combined analysis of the COSY, TOCSY, and HMBC NMR spectra. An array of COSY and TOCSY correlations from $\mathrm{H}-2$ to $5-\mathrm{NH}$ through $\mathrm{H}_{2}-3, \mathrm{H}_{2}-4$, and $\mathrm{H}_{2}-5$ identified a four-carbon spin system building piperazic acid. In addition, one more piperazic acid unit was established from the COSY correlations among $\mathrm{H}-13, \mathrm{H}_{2}-14, \mathrm{H}_{2}-15, \mathrm{H}_{2}-16$, and $16-\mathrm{NH}$, along with the corresponding $\mathrm{HMBC}$ 
signals. Continuous analysis of the COSY, TOCSY and HMBC NMR spectra constructed the other amino acids present, namely, an isoleucine, a valine, a threonine, and two leucine amino acid residues. Therefore, depsidomycin B (1) possesses eight discrete spin systems composed of two piperazic acids (Pip-1 and Pip-2), two leucines (Leu-1 and Leu-2), an isoleucine (Ile), a valine (Val), a threonine (Thr), and a formyl group.

Based on the eight partial structures and the molecular formula, dereplication of depsidomycin B (1) indicated that this compound could have the same planar structure as the previously reported depsidomycin [10,11]. The sequence (Pip-1-Leu-1-Pip-2-Val-Leu-2-Thr-Ile-formamide) of the amino acid residues was confirmed by ${ }^{1} \mathrm{H}-{ }^{13} \mathrm{C} \mathrm{HMBC}$ correlations (Figure 2). The formyl functional group was connected to Ile by 33-NH/H-38 COSY and H-38/C-33 HMBC correlations (Figure 2).

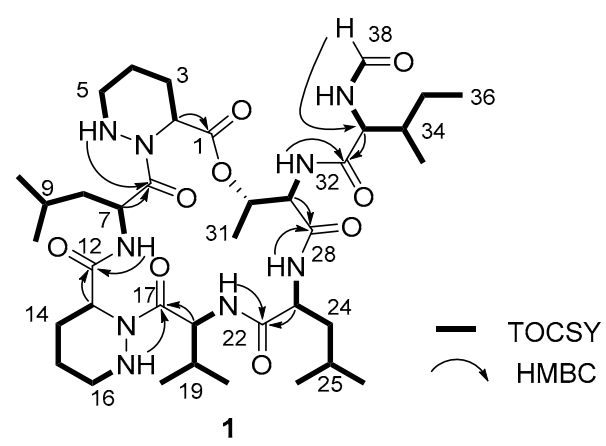

Figure 2. The ${ }^{1} \mathrm{H}-{ }^{1} \mathrm{H}$ TOCSY (bold line) and key HMBC (arrow) correlations of depsidomycin B (1).

The molecular formula $\left(\mathrm{C}_{38} \mathrm{H}_{65} \mathrm{~N}_{9} \mathrm{O}_{9}\right)$ of depsidomycin $\mathrm{B}$ indicated 11 double bond equivalents. Eight carbonyl carbons and two piperazic acid rings accounted for 10 out of the 11 unsaturations, indicating one additional ring was required in the structure of 1 . The 1D and 2D NMR spectra collected in the aprotic solvents acetone- $d_{6}$ and pyridine- $d_{5}$ did not show a signal for the hydroxy proton at the $\beta$-position of Thr, which implied that a tethered lactone ring could be connected to this unit. In addition, the ROESY NMR cross-peak between $\mathrm{H}-2$ and $\mathrm{H}-30\left(\delta_{\mathrm{H}} 4.91\right)$ supported the existence of a macrocyclic ring connecting Pip- 1 and Thr. However, a key HMBC signal from H-30 to C-1 $\left(\delta_{C}\right.$ 169.3), which could unequivocally confirm the presence of such a ring, was not detected in the NMR spectra acquired in these solvents. Therefore, we derivatized depsidomycin B (1) by methanolysis and comprehensively analyzed the 1D and 2D NMR spectra of the derivative (3) (Figures S22-S27). In the HMBC NMR spectrum of the methanolysis product, the methoxy protons $\left(\mathrm{H}-39, \delta_{\mathrm{H}} 3.74\right)$ showed clear correlations with C-1 ( $\left.\delta_{C} 172.1\right)$, establishing the connectivity between Pip-1 and Thr in depsidomycin B (1) through an ester functional group (Table S2). The sequence of the amino acid residues was also confirmed based on the MS/MS spectrum (fragmentation ions at $m / z 243,356,370,455,567$, and 680) of the methanolysis product (Figure 3 and Figure S28). Overall, the planar structure of depsidomycin B (1) was determined to be a cyclic heptapeptide bearing a formamide attached at D-Ile moiety.

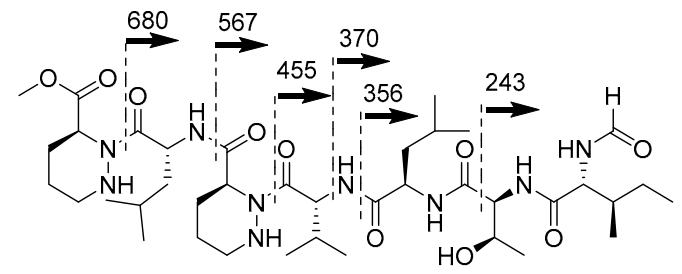

Figure 3. MS/MS fragmentation of the methanolysis product (3) of $\mathbf{1}$.

The planar structure of $\mathbf{1}$ was identical to that reported previously for depsidomycin, which showed antibacterial activity [10,11]. A careful comparison of our NMR data of depsidomycin B with 
the reported data revealed that most of the ${ }^{1} \mathrm{H}$ and ${ }^{13} \mathrm{C}$ chemical shifts are very similar (within 0.02 and $0.2 \mathrm{ppm}$, respectively; Table S3). However, the chemical shifts of 7-NH $\left(\delta_{\mathrm{H}} 7.62\right), 18-\mathrm{NH}\left(\delta_{\mathrm{H}}\right.$ 7.59), 23-NH, and 33-NH $\left(\delta_{\mathrm{H}} 7.49\right)$ in the ${ }^{1} \mathrm{H}$ NMR spectra of the two compounds varied by $0.3 \mathrm{ppm}$. More strikingly, the chemical shifts of $29-\mathrm{NH}$ and $\mathrm{H}-33$ were substantially different; they varied by 0.17 and $0.10 \mathrm{ppm}$, respectively. The ${ }^{13} \mathrm{C}$ NMR chemical shifts at $C-13\left(\delta_{C} 52.8\right), C-34\left(\delta_{C} 38.1\right)$, and C-36 $\left(\delta_{C}\right.$ 11.8 ) varied by $0.3,0.4$, and $0.3 \mathrm{ppm}$, respectively. Moreover, the specific rotation of depsidomycin $B$ $(-1.7)$ was significantly different from that of depsidomycin (-59.7). These spectroscopic differences strongly indicated that depsidomycin B (1) is a stereoisomer of depsidomycin, and its amino acid residues are in different configurations; however, fully elucidating these differences requires extensive stereochemical determinations (see Section 2.2).

Depsidomycin C (2) was purified as a white powder. Its HR-ESI-MS data confirmed a molecular formula of $\mathrm{C}_{37} \mathrm{H}_{63} \mathrm{~N}_{9} \mathrm{O}_{9}$, which has one fewer methylene than does depsidomycin $\mathrm{B}$ (1). The $1 \mathrm{D}$ and 2D NMR spectroscopic data of 2 suggested that its NMR spectroscopic features were quite similar to those of $\mathbf{1}$, indicating that depsidomycin C (2) is structurally analogous to depsidomycin B (1). Comprehensive analysis of its 2D NMR spectra revealed that the isoleucine unit of $\mathbf{1}$ had been replaced with a valine (Val) in $\mathbf{2}$ (Table 1). Thus, the structure of depsidomycin C (2) was elucidated to be a new cyclic heptapeptide with the sequence Pip-1-Leu-Pip-2-Val-1-Leu-2-Thr-Val-2-formamide.

\subsection{Determination of the Absolute Configurations of Depsidomycins B and C}

The absolute configurations of the amino acids were determined by advanced Marfey's method [12,13] and 2,3,4,6-tetra-O-acetyl- $\beta$-D-glucopyranosyl isothiocyanate (GITC) derivatization followed by LC/MS analysis [14]. The acid hydrolysate of $\mathbf{1}$ was derivatized with Marfey's reagents, $\mathrm{N}$-(5-fluoro-2,4-dinitrophenyl)-L-alanine amide (L-FDAA) and D-FDAA. The elution sequences of the L- and D-FDAA derivatives (elution order: $\mathrm{D} \rightarrow \mathrm{L}$ for Val, Leu, Thr, and Ile) in the LC/MS chromatography established that the valine, leucine, threonine and isoleucine residues are in the D-configuration (Table S4, Figure S29). Piperazic acid causes the D-FDAA derivatives to elute before the L-FDAA derivatives when it is in the $S$-configuration [15]. In the LC/MS chromatogram, the D-FDAA adduct of the piperazic acid units eluted faster than did the L-FDAA derivative, which confirmed the two piperazic acids in $\mathbf{1}$ were in the S-configuration (Table S4). The absolute configurations of the $\beta$-carbons of D-threonine and D-isoleucine were assigned by GITC derivatization and LC/MS analysis. The chromatogram of the GITC adducts of the hydrolysate of depsidomycin B (1) displayed retention times consistent with those of D-Thr and D-Ile rather than D-allo-Thr and D-allo-Ile. This assignment was further confirmed by co-injecting the GITC derivatives of authentic D-Thr, D-allo-Thr, D-Ile, and D-allo-Ile individually with the GITC derivative of $\mathbf{1}$. Based on advanced Marfey's analysis and GITC derivatization, the absolute configurations of the amino acid units common to $\mathbf{1}$ and $\mathbf{2}$ were identical (Figures S30-S32). The additional valine residue in depsidomycin C (2), which replaced the D-Ile unit in $\mathbf{1}$, was determined to be $\mathrm{D}-\mathrm{Val}$.

Overall, depsidomycin B (1) was determined to contain D-valine, D-threonine, D-isoleucine, two D-leucines and two S-piperazic acids, whereas depsidomycin contains D-valine, L-threonine, L-allo-isoleucine, L-leucine, D-leucine, and two configurationally-undetermined piperazic acids. The differences in the NMR chemical shifts (Table S3) and the optical rotations of depsidomycin $B$ and depsidomycin, which have identical planar structures, could be explained by the differences in their stereochemistries.

\subsection{Biological Activity of Depsidomycins B and C}

Even though depsidomycin was originally reported to show antibacterial activity against Micrococcus luteus, depsidomycins B and C did not exhibit antibacterial activity against M. luteus in our tests. These cyclic peptides did not inhibit the growth of any in vitro-tested bacteria (Gram positive: Staphylococcus aureus ATCC 25923, Enterococcus faecalis ATCC 19433, and Enterococcus faecium ATCC 19434; Gram negative: Micrococcus luteus ATCC 9341, Klebsiella pneumoniae ATCC 10031, 
Salmonella enterica ATCC 14028, Escherichia coli ATCC 25922) and fungi (Aspergillus fumigatus HIC 6094, Trichophyton rubrum NBRC 9185, Trichophyton mentagrophytes IFM 40996, and Candida albicans ATCC 10231) [16], or cancer cell lines (MDA-MB-231, A549, HCT116, SK-HEP-1, SNU638, and K562) [17]. Therefore, their biological activities were further evaluated with respect to their antimetastatic activities against MDA-MB-231 cells (a metastatic breast cancer cell line) in a wound-healing assay [18]. After mechanically generating scratches in MDA-MB-231 cells, the cells were treated with vehicle or depsidomycins $B$ and $C$ for $24 \mathrm{~h}$. The wounds were photographed at $0 \mathrm{~h}$ (immediately after wounding) and $24 \mathrm{~h}$ with an inverted microscope. Compared to the vehicle-treated group, cell migration (antimetastatic effect) was suppressed in the depsipeptide-treated groups. The remaining cell-free area (\%) calculated $24 \mathrm{~h}$ after wounding of the vehicle-treated group was $22 \%$, while those of the depsidomycin B-treated groups (20 and $40 \mu \mathrm{M}$ ) were $56 \%$ and $82 \%$, respectively (Figures 4 and 5). Depsidomycin C displayed less potent activity, as it provided $47 \%$ and $70 \%$ remaining cell-free area at 20 and $40 \mu \mathrm{M}$, respectively (Figures 4 and 5). This result indicated that depsidomycins B and C (1 and 2) have significant dose-dependent antimetastatic effects on the metastatic breast cancer cell line MDA-MB-231 in vitro.
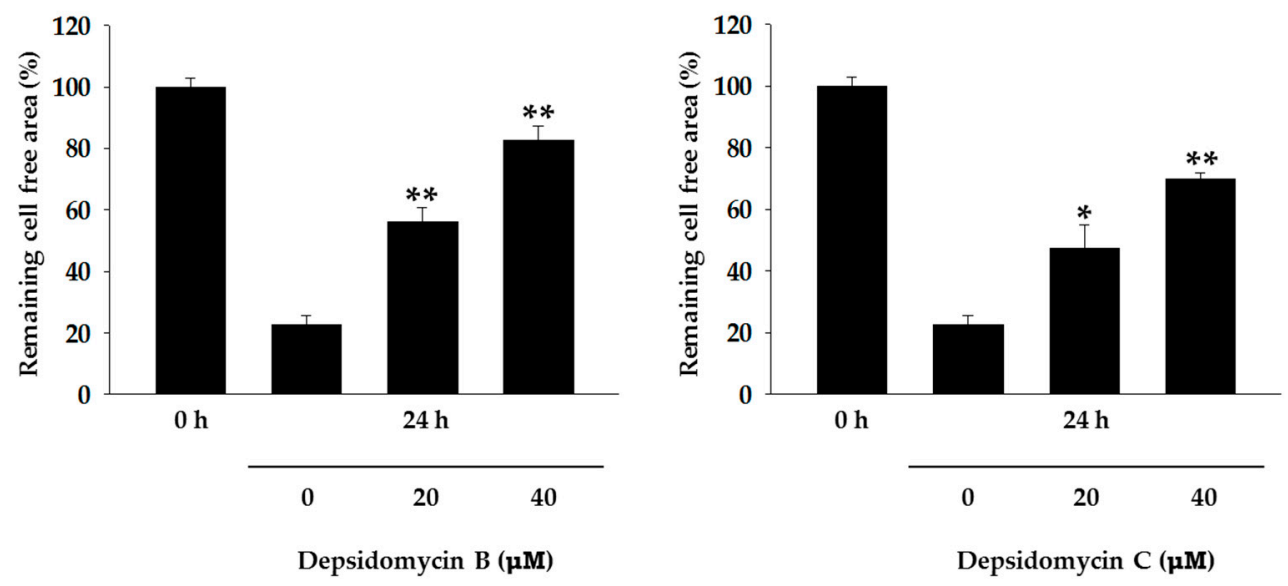

Figure 4. Remaining cell-free area (\%) of MDA-MB-231 cells treated with depsidomycin B (1) and C (2). All data are expressed as the means $\pm \mathrm{SD}(n=3) .{ }^{*} p<0.05$. ${ }^{* *} p<0.01$ compared to the control.

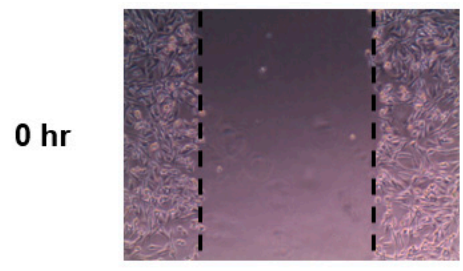

$24 \mathrm{hr}$

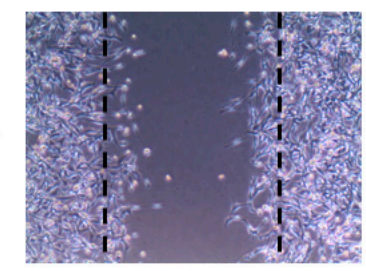

Depsidomycin B

$20 \mu \mathrm{M}$

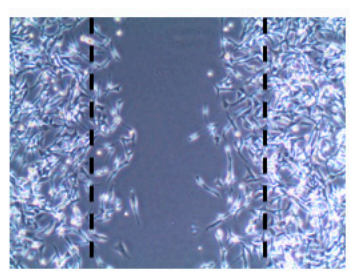

Depsidomycin C

$20 \mu \mathrm{M}$

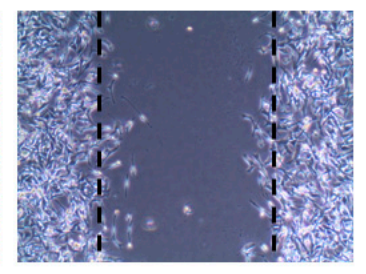

Depsidomycin B $40 \mu \mathrm{M}$

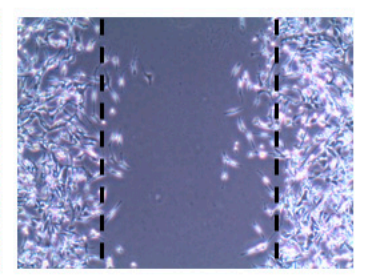

Depsidomycin C $40 \mu \mathrm{M}$

Figure 5. Antimetastatic activity against the breast cancer cell line MDA-MB-231. 


\section{Experimental Section}

\subsection{General Experimental Procedures}

The optical rotations were recorded with a JASCO P-1020 polarimeter. UV spectra were measured on a Perkin-Elmer (Waltham, MA, USA) Lambda 35 UV/VIS spectrometer. IR spectra were recorded on a JASCO FT-IR-4200 spectrometer. ${ }^{1} \mathrm{H}$ NMR $(850 \mathrm{MHz}, 600 \mathrm{MHz})$ and ${ }^{13} \mathrm{C} \mathrm{NMR}(212.5 \mathrm{MHz}, 150 \mathrm{MHz})$ spectral data were obtained on a Bruker (Billerica, MA, USA) Avance 3 HD and Avance-600 at NCIRF (National Center for Inter-University Research Facilities, Seoul, Republic of Korea). Low-resolution LC/MS data were acquired on an Agilent Technologies (Santa Clara, CA, USA) 1200 series HPLC coupled with an Agilent Technologies (Santa Clara, CA, USA) 6130 quadrupole mass spectrometer. High-resolution electrospray ionization mass spectrometry (HR-ESI-MS) data were collected with a Thermo (Waltham, MA, USA) Finnigan LTQ high-resolution mass spectrometer at NICEM (National Instrumentation Center for Environmental Management, Seoul, Republic of Korea). LC-MS/MS data were obtained with an AB SCIEX Q-TOF 5600 at NICEM and a Waters (Milford, MA, USA) XEVO G2S Q-TOF mass spectrometer at Ewha Womans University (Seoul, Republic of Korea).

\subsection{Bacterial Isolation}

The soil samples were collected from a four-year ginseng farm in Cheorwon, Gangwon-do, Republic of Korea. The samples were dried at room temperature (rt) for $5 \mathrm{~h}$, and the dry soil (1 g) was mixed with $8 \mathrm{~mL}$ of sterilized water. The supernatant of the mixture was inoculated onto TWYE agar (TWYE: $1 \mathrm{~L}$ of tap water, $18 \mathrm{~g}$ of agar, $0.25 \mathrm{~g}$ of yeast extract and $0.5 \mathrm{~g}$ of $\mathrm{K}_{2} \mathrm{HPO}_{4}$ ) and then spread. Colonies were repeatedly isolated onto fresh agar plates to obtain single strains. The strain BYK1371 (GenBank accession no. MH037157) was phylogenetically identified as a Streptomyces sp. by the phylogenetic tree based on 16S rRNA gene sequence analysis. It is most closely related to Streptomyces vinaceus NRBC 13425 and Streptomyces cirratus NRRL B-3250 (Figure S35).

\subsection{Cultivation and Extraction of the Bacterial Strain}

The BYK1371 strain was cultured on solid YEME medium (4 g of yeast extract, $10 \mathrm{~g}$ of malt extract, $4 \mathrm{~g}$ of glucose, and $18 \mathrm{~g}$ of agar per $1 \mathrm{~L}$ of sterilized water) at $27^{\circ} \mathrm{C}$. The culture was then transferred to $50 \mathrm{~mL}$ of liquid YEME medium in a $125 \mathrm{~mL}$ Erlenmeyer flask. After incubation at $25{ }^{\circ} \mathrm{C}$ with shaking at $180 \mathrm{rpm}$ for 2 days, $20 \mathrm{~mL}$ of the culture was inoculated into each of the $2.8 \mathrm{~L}$ Fernbach flask containing $1 \mathrm{~L}$ of YEME liquid medium. The cultures were cultivated at $27^{\circ} \mathrm{C}$ with shaking at $140 \mathrm{rpm}$ for five days because the yields of $\mathbf{1}$ and $\mathbf{2}$ were the best for harvest based on the time-course LC/MS analysis of the strain (Figure S34). In total, $85 \mathrm{~L}$ of culture was prepared for the isolation of 1 and 2. The combined total culture (85 L) was extracted twice with $200 \mathrm{~L}$ of EtOAc using a 3-L separation funnel. After adding anhydrous sodium sulfate to remove the residual water, the EtOAc layer was concentrated in vacuo to yield $13.2 \mathrm{~g}$ of extract.

\subsection{Isolation of Depsidomycin B (1) and C (2)}

An aliquot (4.3 g) of the extract was resuspended in $\mathrm{MeOH}$ and dried onto Celite in vacuo to generate a Celite-adsorbed extract mixture. The mixture was loaded onto $20 \mathrm{~g}$ of prepacked $\mathrm{C}_{18}$ Sepak resin. The extract was fractionated by elution with a step gradient solvent system composed of $\mathrm{MeOH}$ and $\mathrm{H}_{2} \mathrm{O}\left(20 \%, 40 \%, 60 \%, 80 \%\right.$, and $100 \% \mathrm{MeOH}$ in $\left.\mathrm{H}_{2} \mathrm{O}\right)$. Depsidomycins $\mathrm{B}$ and $\mathrm{C}(\mathbf{1}$ and 2$)$ eluted in the $80 \%$ aqueous $\mathrm{MeOH}$ fraction. To obtain pure compounds, further purification was performed using an analytical reverse-phase HPLC system (Phenomenex, Torrance, CA, USA) Luna $10 \mu \mathrm{m} \mathrm{C}_{8}(2)$ $250 \times 4.6 \mathrm{~mm}, 35 \%$ to $70 \%$ aqueous $\mathrm{CH}_{3} \mathrm{CN}$ as the solvent gradient system over $40 \mathrm{~min}$, flow rate of 1 $\mathrm{mL} / \mathrm{min}$, and UV detection at $210 \mathrm{~nm})$. Depsidomycin B (1, 23.6 mg) and C (2, 7.3 mg) were collected at retention times of $28 \mathrm{~min}$ and $25 \mathrm{~min}$, respectively. 
Depsidomycin B (1): white powder; $[\alpha]_{\mathrm{D}}^{25}-1.7$ (c 0.2, MeOH); UV (MeOH) $\lambda_{\max }(\log \varepsilon) 201(2.31) \mathrm{nm}$; IR (neat) $\lambda_{\max } 3407,2843,1646,1451,1017 \mathrm{~cm}^{-1} ;{ }^{1} \mathrm{H}$ and ${ }^{13} \mathrm{C}$ NMR data, see Table 1 ; HR-ESI-MS $m / z$ $814.4799[\mathrm{M}+\mathrm{Na}]^{+}$(calcd for $\mathrm{C}_{38} \mathrm{H}_{65} \mathrm{~N}_{9} \mathrm{O}_{9} \mathrm{Na}, 814.4798$ ).

Depsidomycin C (2): white powder; $[\alpha]_{\mathrm{D}}^{25}-0.01$ (c 0.2, MeOH); UV (MeOH) $\lambda_{\max }(\log \varepsilon) 200$ (2.29) nm; IR (neat) $\lambda_{\max } 3375,2948,1657,1451,1024 \mathrm{~cm}^{-1} ;{ }^{1} \mathrm{H}$ and ${ }^{13} \mathrm{C}$ NMR data, see Table 1 ; HR-ESI-MS $m / z$ $800.4640[\mathrm{M}+\mathrm{Na}]^{+}$(calcd for $\mathrm{C}_{37} \mathrm{H}_{63} \mathrm{~N}_{9} \mathrm{O}_{9} \mathrm{Na}, 800.4641$ ).

\subsection{Determination of the Absolute Configurations of the $\alpha$-Carbons of the Amino Acid Residues}

Depsidomycin B $(1 \mathrm{mg})$ was hydrolyzed in $0.5 \mathrm{~mL}$ of $6 \mathrm{~N} \mathrm{HCl}$ at $115^{\circ} \mathrm{C}$. After $90 \mathrm{~min}$, the reaction vial was cooled to $0^{\circ} \mathrm{C}$ in ice for $3 \mathrm{~min}$. Then, the $\mathrm{HCl}$ in the reaction vial was removed in vacuo. The dry material was dissolved again in $1 \mathrm{~mL}$ of $\mathrm{H}_{2} \mathrm{O}$ and dried in vacuo. This process was repeated three times to completely remove the $\mathrm{HCl}$. The hydrolysate was divided into two portions, and each portion was transferred to a 4-mL vial. To each vial, $100 \mu \mathrm{L}$ of $1 \mathrm{~N} \mathrm{NaHCO}_{3}$ was added to dissolve the hydrolysate. Then, $50 \mu \mathrm{L}$ of either $10 \mathrm{mg} / \mathrm{mL}$ L-FDAA (L-fluoro-2,4-dinitrophenyl-5-L-alanine amide) or D-FDAA in acetone was added to the vials. After the reaction was maintained at $80{ }^{\circ} \mathrm{C}$ in a water bath for $3 \mathrm{~min}, 50 \mu \mathrm{L}$ of $2 \mathrm{~N} \mathrm{HCl}$ was added to quench the reaction by neutralization. Additionally, $300 \mu \mathrm{L}$ of $50 \%$ aqueous $\mathrm{CH}_{3} \mathrm{CN}$ was added to the solution to dissolve the reaction products. A $10-\mu \mathrm{L}$ aliquot of each reaction mixture was analyzed by LC/MS with a gradient solvent system $(20 \%$ to $60 \%$ $\mathrm{CH}_{3} \mathrm{CN}$ with $0.1 \%$ formic acid over $\left.40 \mathrm{~min}\right)$ on a $\mathrm{C}_{18}$ reversed-phase column $(100 \times 4.6 \mathrm{~mm})$ with UV detection at $210 \mathrm{~nm}$ (Table S4). The absolute configurations of the amino acid residues in depsidomycin $\mathrm{C}$ (2) were determined using the procedure described above.

\subsection{Determination of the Absolute Configurations at the $\beta$-Carbons of Threonine and Isoleucine}

The hydrolysates of 1 and 2 were dissolved in $\mathrm{H}_{2} \mathrm{O}(1 \mathrm{mg} / \mathrm{mL})$ in two separate 4-mL vials. Then, $100 \mu \mathrm{L}$ of $1 \%$ GITC (2,3,4,6-tetra-O-acetyl- $\beta$-D-glucopyranosyl isothiocyanate) in acetone and $100 \mu \mathrm{L}$ of $6 \%$ triethylamine were added to each vial. Each reaction mixture was stirred for $15 \mathrm{~min}$ at $\mathrm{rt}$, and then $100 \mu \mathrm{L}$ of $5 \%$ acetic acid was added to dilute the reaction mixtures. The products were analyzed by LC/MS under different gradient solvent systems $\left(10 \%\right.$ to $100 \% \mathrm{CH}_{3} \mathrm{CN}$ with $0.1 \%$ formic acid over $20 \mathrm{~min}$ on a Phenomenex Luna $\mathrm{C}_{18}$ reversed-phase column, $100 \times 4.6 \mathrm{~mm}$, for Thr, and $30 \%$ to $55 \% \mathrm{CH}_{3} \mathrm{CN}$ with $0.1 \%$ formic acid over $80 \mathrm{~min}$ on a Phenomenex Luna $\mathrm{C}_{18}$ reversed-phase column, $250 \times 4.6 \mathrm{~mm}$, for Ile). Detection at $210 \mathrm{~nm}$ was performed by a UV detector. The authentic standards of D-Thr, D-allo-Thr, D-Ile and D-allo-Ile were also derivatized with GITC by using the identical method. The GITC-derivatized products for D-Thr in $\mathbf{1}$ and 2 eluted at 9.4 min, indicating that the threonine units in $\mathbf{1}$ and $\mathbf{2}$ are D-Thr and not D-allo-Thr. The GITC adduct of D-Ile in $\mathbf{1}$ was detected at $53.7 \mathrm{~min}$, which establish that this residue is D-Ile and not D-allo-Ile. Then, the GITC derivatives of the hydrolysate were co-injected with the GITC derivatives of each of the standards (D-Thr, D-allo-Thr, D-Ile and D-allo-Ile) to confirm the assignments. The GITC derivatives of authentic D-Thr, D-allo-Thr, D-Ile and D-allo-Ile eluted at 9.4, 9.6, 53.7 and $52.3 \mathrm{~min}$, respectively, confirming the configurations of the $\beta$-carbons of D-Thr and D-Ile.

\subsection{Methanolysis of Depsidomycin B (1)}

Depsidomycin B (1, $8 \mathrm{mg}$ ) was dissolved in $2 \mathrm{~mL}$ of $\mathrm{MeOH}$, and $11.2 \mathrm{mg}$ of $\mathrm{NaOMe}$ was added to the vial to prepare a $0.5 \mathrm{M} \mathrm{NaOMe}$ solution. The reaction mixture was stirred at r.t. for $3 \mathrm{~h}$, and the reaction was quenched with $1 \mathrm{~N} \mathrm{HCl}$. After evaporating the $\mathrm{MeOH}$ in vacuo, the residue of the methanolysis reaction was partitioned into $\mathrm{H}_{2} \mathrm{O}$ and EtOAc. After removing the solvent, the methanolysis products (3,6 mg) were purified on a Sephadex LH-20 (GE Healthcare, Chicago, IL, USA) open column using $\mathrm{MeOH}$ as the eluent. The structure of the methanolysis product (3) was assigned by analyzing its $1 \mathrm{D}$ and 2D NMR and LC-MS/MS data. For ${ }^{1} \mathrm{H}$ and ${ }^{13} \mathrm{C}$ NMR data, see Table S2, HR-ESI-MS $m / z 824.5252[\mathrm{M}+\mathrm{H}]^{+}$(calcd. for $\mathrm{C}_{39} \mathrm{H}_{70} \mathrm{~N}_{9} \mathrm{O}_{10}$ 824.5245). 


\subsection{Evaluation of Antimetatastic Activity}

MDA-MB-231 cells were used to measure the antimetastatic activities of $\mathbf{1}$ and $\mathbf{2}$ based on the wound-healing assay method described previously in the literature [18]. Sunitinib was used as a positive control (Figure S33).

\subsection{Statistical Analysis}

Data are expressed as the mean \pm standard deviation (SD) for the indicated number of independently performed experiments. Statistical significance was analyzed using a Student's $t$-test or one-way analysis of variance (ANOVA) coupled with a Dunnett's $t$-test. Differences were considered statistically significant at $p<0.05,{ }^{* *} p<0.01$.

\section{Conclusions}

Depsidomycins B and C (1 and 2) are new cyclic heptapeptides bearing modified amino acid residues including two S-piperazic acids and D-Leu, D-Val, D-Thr, and D-Ile (D-Val for 2), along with formyl groups at their $N$-termini. Even though the planar structure of depsidomycin B (1) is identical to that of the previously reported compound depsidomycin, the absolute configurations of the amino acids in $\mathbf{1}$ are clearly different from those in depsidomycin [10]. In addition, considering that the piperazic acid units in the original literature on depsidomycin were not configurationally assigned [10], this work constitutes the first report of new members of the depsidomycin class of cyclic peptides and the first complete stereochemical structure elucidation of these compounds. The discovery of these new compounds from a Streptomyces sp. strain isolated from ginseng farm soil based on a time-course LC/MS analysis of its metabolite profiles suggests that the investigation of farm soil-derived actinomycetes using a chemical analysis-based search strategy could provide an additional route for the effective discovery of new bioactive natural products.

Supplementary Materials: The supplementary materials are available online.

Author Contributions: Y.K., M.B., J.S., S.K.L., and D.-C.O. designed the experiments; B.-Y.K. isolated the bacterial strain and performed the phylogenetic analysis; Y.K. performed the chemical experiments and analyzed the data; W.S.B. and S.K.L. performed the bioassay; M.C.S. and Y.J.Y. performed the MS/MS experiments; Y.K., W.S.B., B.-Y.K., M.C.S., M.B., Y.J.Y., J.S., S.K.L., and D.-C.O. wrote the paper.

Funding: This work was supported by a National Research Foundation (NRF) of Korea grant funded by the Korean Government Ministry of Science and ICT (No. 2009-0083533).

Conflicts of Interest: The authors declare no conflict of interest.

\section{References}

1. Bérdy, J. Thoughts and facts about antibiotics: Where we are now and where we are heading. J. Antibiot. 2012, 65, 385-395. [CrossRef] [PubMed]

2. Müller, R.; Krug, D. Secondary metabolomics: The impact of mass spectrometry-based approaches on the discovery and characterization of microbial natural products. Nat. Prod. Rep. 2014, 31, 768-783.

3. Bae, M.; Oh, J.; Bae, E.S.; Oh, J.; Hur, J.; Suh, Y.-G.; Lee, S.K.; Shin, J.; Oh, D.-C. WS9326H, an antiangiogenic pyrazolone-bearing peptide from an intertidal mudflat actinomycete. Org. Lett. 2018, 20, $1999-2002$. [CrossRef] [PubMed]

4. Shin, B.; Park, S.H.; Kim, B.-Y.; Jo, S.-I.; Lee, S.K.; Shin, J.; Oh, D.-C. Deinococcucins A-D, aminoglycolipids from Deinococcus sp., a gut bacterium of the carpenter ant Camponotus japonicus. J. Nat. Prod. 2017, 80, 2910-2916. [CrossRef] [PubMed]

5. Um, S.; Bach, D.-H.; Shin, B.; Ahn, C.-H.; Kim, S.-H.; Bang, S.-H.; Oh, K.-B.; Lee, S.K.; Shin, J.; Oh, D.-C. Naphthoquinon-oxindole alkaloids, coprisidins A and B, from a gut-associated bacterium in the dung beetle, Copris tripartitus. Org. Lett. 2016, 18, 5792-5795. [CrossRef] [PubMed]

6. Keohane, C.E.; Steele, A.D.; Wuest, W.M. The rhizosphere microbiome: A playground for natural product chemists. Synlett 2015, 26, 2739-2744. 
7. Shin, B.; Kim, B.-Y.; Cho, E.; Oh, K.-B.; Shin, J.; Goodfellow, M.; Oh, D.-C. Actinomadurol, an antibacterial norditerpenoid from a rare Actinomycete, Actionmadura sp. KC 191. J. Nat. Prod. 2016, 79, 1886-1890. [CrossRef] [PubMed]

8. Baeg, I.; So, S.H. The world ginseng market and the ginseng (Korea). J. Ginseng Res. 2013, 37, 1-7. [CrossRef] [PubMed]

9. Sub, B.S.; Xu, M.Y.; Li, Z.; Wang, Y.B.; Sung, C.K. UPLC-Q-TOF-MS/MS analysis for steaming times-dependent profiling of steamed Panax quiquefolius and its ginsenosides transformations induced by repetitious steaming. J. Ginseng Res. 2012, 36, 277-290.

10. Isshiki, K.; Sawa, T.; Naganawa, H.; Koizumi, Y.; Matsuda, N.; Hamada, M.; Takeuchi, T. Depsidomycin, a new immunomodulating antibiotic. J. Antibiot. 1990, 43, 1195-1198. [CrossRef] [PubMed]

11. Narayanaswamy, V.K.; Albericio, F.; Coovadia, Y.M.; Kruger, H.G.; Maguire, G.E.M.; Pillay, M.; Govender, T. Total synthesis of depsidomycin analogue by convergent solid-phase peptide synthesis and macrolactonization strategy for antitubercular activity. J. Pept. Sci. 2011, 17, 683-689. [CrossRef] [PubMed]

12. Fujii, K.; Ikai, Y.; Mayumi, T.; Oka, H.; Suzuki, M.; Harada, K. A nonempirical method using LC/MS for determination of the absolute configuration of constituent amino acids in a peptide: Elucidation of limitations of marfey's method and of its separation mechanism. Anal. Chem. 1997, 69, 3346-3352. [CrossRef]

13. Fujii, K.; Ikai, Y.; Oka, H.; Suzuki, M.; Harada, K. A nonempirical method using LC/MS for determination of the absolute configuration of constituent amino acids in a peptide: Combination of Marfey's method with mass spectrometry and its practical application. Anal. Chem. 1997, 69, 5146-5151. [CrossRef]

14. Hess, S.; Gustafson, K.R.; Milanowski, D.J.; Alvira, E.; Lipton, M.A.; Pannell, L.K. Chirality determination of unusual amino acids using precolumn derivatization and liquid chromatography-electrospray ionization mass spectrometry. J. Chromatogr. A 2004, 1035, 211-219. [CrossRef] [PubMed]

15. Oh, D.-C.; Poulsen, M.; Currie, C.R.; Clardy, J. Dentigerumycin: A bacterial mediator of an ant-fungus symbiosis. Nat. Chem. Biol. 2009, 5, 391-393. [CrossRef] [PubMed]

16. Shin, Y.-H.; Bae, S.; Sim, J.; Hur, J.; Jo, S.-I.; Shin, J.; Suh, Y.-G.; Oh, K.-B.; Oh, D.-C. Nicrophorusamides A and $\mathrm{B}$, antibacterial chlorinated cyclic peptides from a gut bacterium of the carrion beetle Nicrophorus concolor. J. Nat. Prod. 2017, 80, 2962-2968. [CrossRef] [PubMed]

17. Vichai, V.; Kirtikara, K. Sulforhodamine B colorimetric assay for cytotoxicity screening. Nat. Protoc. 2006, 1, 1112-1116. [CrossRef] [PubMed]

18. Kim, W.K.; Byun, W.S.; Chung, H.-J.; Oh, J.; Park, H.J.; Choi, J.S.; Lee, S.K. Esculetin suppresses tumor growth and metastasis by targeting Axin2/E-cadherin axis in colorectal cancer. Biochem. Pharmacol. 2018, 152, 71-83. [CrossRef] [PubMed]

Sample Availability: Samples of the compounds depsidomycins B and C are available from the authors.

(C) 2018 by the authors. Licensee MDPI, Basel, Switzerland. This article is an open access article distributed under the terms and conditions of the Creative Commons Attribution (CC BY) license (http:/ / creativecommons.org/licenses/by/4.0/). 